\title{
Observed failures at railway turnouts: failure analysis, possible causes and links to current and future research
}

\author{
Ilaria Grossoni ${ }^{1 a}$, Peter Hughes ${ }^{a}$, Yann Bezin ${ }^{a}$, Adam Bevan ${ }^{a}$, Jay Jaiswal ${ }^{a}$ \\ ${ }^{a}$ Institute of Railway Research, University of Huddersfield, Huddersfield, UK
}

\begin{abstract}
Railway turnouts are a necessary part of railway infrastructure, used throughout the network to direct trains to the desired path, thus ensuring the smooth running of every train. Their reliability and availability is therefore an essential element for the efficiency of the entire network. However, the combination of movable parts, some of which with reducing cross sections and structural integrity, discontinuities in the rail geometry and variability in the system support stiffness leads to high failure rates compared with plain line track and to very high maintenance and renewal costs. In this paper, the database of failures occurred in the GB network between 2011 and 2017 has been statistically investigated with the support of free-text analysis techniques to interrogate the comments provided by the on-track maintenance staff. The key failures and possible causes have been identified for both the switch and crossing panels as well as areas for future research to support the development of the next generation of switches and crossings.
\end{abstract}

\section{Keywords}

Railway turnout, S\&Cs, switch panel, crossing panel, wear, RCF, fatigue, plastic deformations, statistical analysis, free-text search.

\section{Introduction}

Railway turnouts, also known as switches and crossings (S\&C) are used throughout the GB railway network in order to direct trains onto the desired path. Their performance is influenced by the presence of movable parts, discontinuities in the rail geometry and variability in the track support stiffness. The combination of these contributes to a high failure rates compared with plain line track [1] and to very high maintenance and renewal costs. According to Cornish [2], S\&Cs have historically taken $24 \%$ of the maintenance budget and $23 \%$ of the renewal against $5 \%$ of the track miles. Common observed failures at $\mathrm{S} \& \mathrm{Cs}$ include wear, plastic deformation and fractures.

Some failure analyses and failure catalogues of turnouts are present in the literature. For example, a very detailed failure catalogue has been issued as part of the European project Capacity4Rail [3]. It has been organised on the basis of failure location, such as switch panel, crossing area, check rails, plates, fastenings, bearers, driving and locking device and ballast bed. It also includes illustrative

1 Corresponding author: Ilaria Grossoni, Institute of Railway Research, University of Huddersfield, Queensgate, HD1 3DH Huddersfield (UK), i.grossoni@ hud.ac.uk, Tel: +44 (0)1484 471179 
examples, very detailed descriptions, causes and possible corrective measures. However, it lacks details of percentage occurrence of each of failure modes. Similarly to the Capacity4Rail catalogue, Hassankiadeh [4] proposes an illustrative failure catalogue divided by component (i.e. rail, sleeper, ballast, subgrade). A Failure Modes and Effects Analysis (FMEA) has been proposed based on data from the GB network for year 2009. More recently, Cornish [5] analysed the GB network data between 2009 and 2013 in terms of failures and delay minutes depending on the switch type and showed how the most common mechanism is plastic deformation for short switches and wear for long switches. Focusing only on the Point Operating Equipment (POE), a complete failure analysis for the GB network and the Swedish network has been presented within the European Project In2Rail [6]. Nevertheless, none of the listed research looked at additional information given by the railway technicians in the form of free-text comments where entries are missing. This is probably because of the significant amount of resources needed for a manual analysis [7]. It is worth mentioning that in the past years, fatigue analysis methods have been used in combination with advanced numerical tools to predict failures on the turnout locations, for example in Ringsberg [8], Xin [9, 10], and Johansson [11].

It is common that railway infrastructure managers have a database where they report each identified defect or failure on the network. For example, Network Rail, which is the GB infrastructure owner and manager, uses the Rail Defect Management System (RDMS). From this database it is possible to extract several types of useful information, including the location (i.e. route and site name), type of rail (i.e. left/right rail, $\mathrm{S} \& \mathrm{C}$ panel), assembly type, track category and track code, rail profile and steel grade. As previously mentioned, additional information can be obtained using the free-text comments that usually accompanies the database despite the high resource consumptions required. It has been demonstrated, however, that the effort required can be reduced by applying semi-automated techniques $[12,13]$. Many researchers have considered the task of extracting information from text data, such as in the health and medical domain (for example [14, 15]) aviation domain (for example [16]), the automotive safety (for example [17]) as well as to obtain information from social media (for example [18]). Applying a thematic approach, Hughes [19] categorised source text according to the occurrence of terms in the text, where a term is either a single word or sequence of consecutive words (also known as an $n$-gram). The selection of terms to categorise text is a manual process since effective categorisation requires knowledge of the domain and an understanding of how the results of the analysis are to be used (Hughes [20]).

It is clear how an in-depth failure analysis over various years can help the infrastructure manager to choose better solutions for preventing damage mechanisms. Thus, the main aim of this paper is to carry out a failure analysis at the S\&Cs based on the large database of reported defects with the support of advance techniques for the free-text analysis, which is the main novelty of this paper. The main causes for failure are identified to support research in to the next generation of turnouts.

The following section describes the main observed failures occurring at S\&Cs, categorised by the location at which they occur, including some illustrative examples and possible causes. Section 3 shows the failure statistical analysis and the free-text analysis of reported defects between 2011 and 2017, with commentary on possible design improvements. Some research linked with the main observed failures as well as areas of potential new ones have been identified in Section 4. Finally, the conclusions have been summarised in Section 5 .

\section{Commonly observed failures at S\&C}

Figure 1 shows a typical layout for a right-hand turnout, which the vehicle can negotiate in four 
routes, nominally the through (i.e. straight track) and diverging routes (i.e. curved track) in the facing (i.e. switch towards the crossing) or trailing direction (i.e. crossing towards the switch). Three main assembly types (or panels) are identified, i.e. the switch panel, the closure panel and the crossing panel.

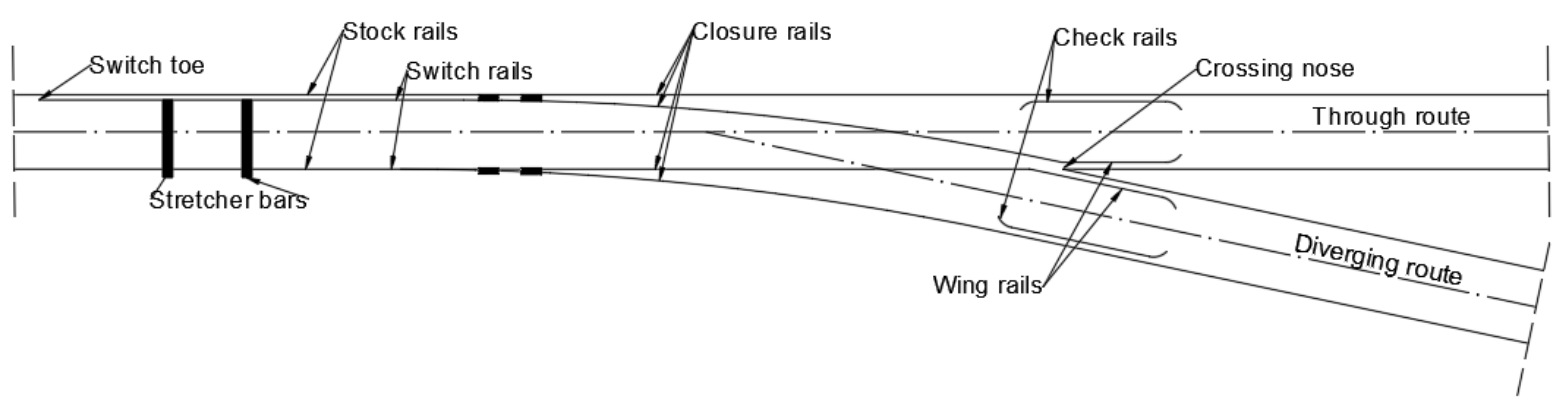

Figure 1: Components of a single right-hand turnout.

Three main types of damage mechanism will be analysed hereafter in both the switch panel and the crossing panel:

\section{- $\underline{\text { Wear }}$}

Wear happens when particles of material are detached due to the differential velocity between wheel and rail. In general, there are five main categories of wear type, which are the oxidative wear (i.e. detachment of oxide layer form the surface), the adhesive wear (i.e. wear process where the contact between surfaces are at discrete locations), the abrasive wear (i.e. damage due to a harder surface or hard particles), the delamination wear (i.e. cracks at the plastically deformed surface layer and the, thermal wear (i.e. due to frictional heating of the surfaces) [21]. In the context of wheel/rail contact, the predominant types are adhesive wear and delamination wear, which is the most severe causing a rougher surface than the abrasive wear type [22].

\section{- Fatigue}

During its life cycle, rails and wheels are both subjected to very high loading cycles which may lead to material fatigue causing crack initiation and propagation and spalling of material fragments which affect the travelling comfort, noise emissions and dynamic load magnification. The fatigue may also be the reason of catastrophic failures if not detected in due time, such as the Hatfield (UK) derailment in October 2000 [23].

It is possible to divide the fatigue in Rolling Contact Fatigue (RCF), which occurs on the contact surface of both rail and wheel, and bending fatigue, which occurs in all the components of the system due to cyclic loads governing whether fatigue cracks are initiated and how fast they grow.

\section{- Plastic deformations}

Plastic deformations occur when the load exceeds the given material elastic limit and the residual stresses change the internal material microstructure, leading to a permanent deformation. The actual deformation depends on the loading conditions, as the structural response can be elastic shakedown (i.e. the same load can be carried elastically due to the very low residual stresses at the first cycle that has changed the internal structure), cyclic plasticity (i.e. the load exceed the elastic limit, so that there is a steady-state regime where the micro-structure is deformed, leading to local material degradation) and ratcheting (i.e. the load exceed also the plastic shakedown limit and each cycle produces increasing deflections arriving to the final structural collapse) [24]. 


\subsection{Switch panel}

The switch panel includes the stock rails, the switch rails, the stretcher bar and all the switch mechanisms that allow the mechanical change of trajectory (Figure 1).

\subsubsection{Wear}

Wear of the switch/stock rail (Figure 2): The wear can occur simultaneously at the switch and stock rail or can be prevalent in one rail depending on the type of traffic and the main direction. This phenomenon is mainly caused by the high tensile forces the material is subject to and can be easily detected visually. Corrective measures include grinding of the metal flow and, in the worst cases, replacement of the whole assembly.

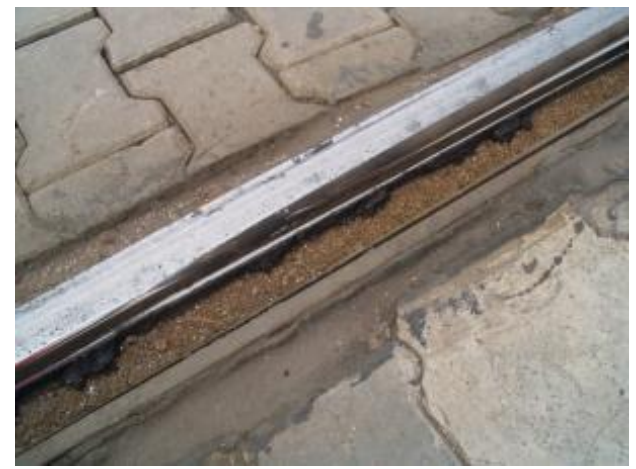

Figure 2: Wear at the stock rail [3].

\subsubsection{Fatigue}

Spalling of the stock rail (Figure 3): The spalling mainly occurs in the wheel transfer area of the switch/stock rail due to the high contact stresses caused by non-optimal wheel/rail contact shape, such as in presence of worn wheels or incorrect profile of the wheel flange. This defect can be detected by visual inspection and can be corrected using deburring tools or grinding the surface. In the most severe cases, though, the replacement of the whole switch and stock rail assembly is required.

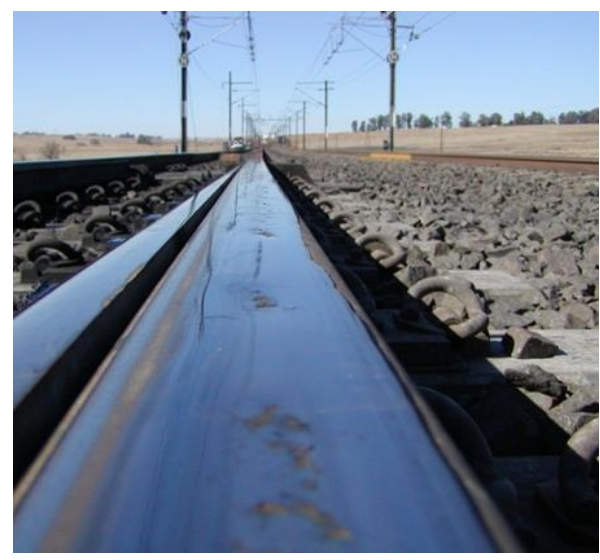

Figure 3: Spalling of the stock rail [3].

Soft spots (Figure 4): Soft spots are mainly present in the forged area of switch rails. They are characterised by a depression in the running surface due to local variation in metal hardness and strength loss caused by temperature changes during forging (i.e. heating and cooling stages). This defect can be detected by visual inspection and requires the replacement of switch rail. 


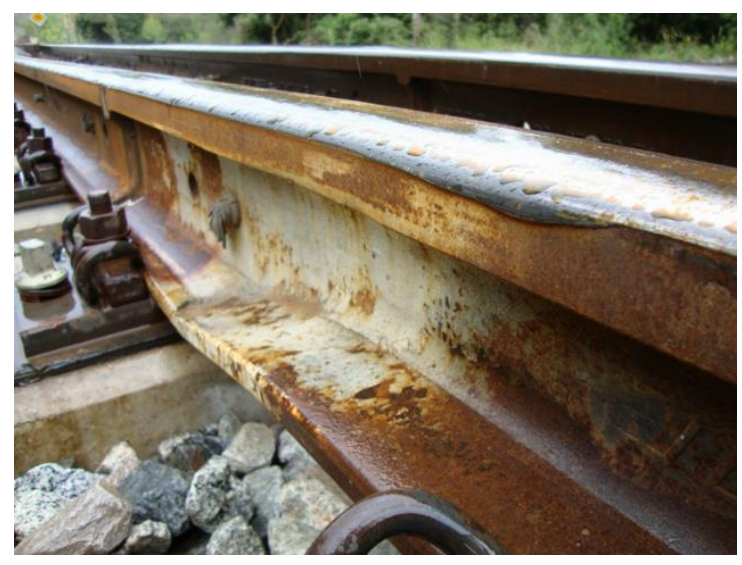

Figure 4: Soft spots [3].

\subsubsection{Plastic deformation}

Lipping (Figure 5): Lipping mainly occurs in the wheel transfer area of the switch/stock rail appearing with a plastically deformed rail, especially at the switch blade, and possibly leading to material breakouts. This defect is caused by high stresses due to non-optimal wheel/rail contact, incorrect profile of wheel flange and poor maintenance. This defect can be detected by visual inspection and requires the replacement of switch and stock rail assembly.

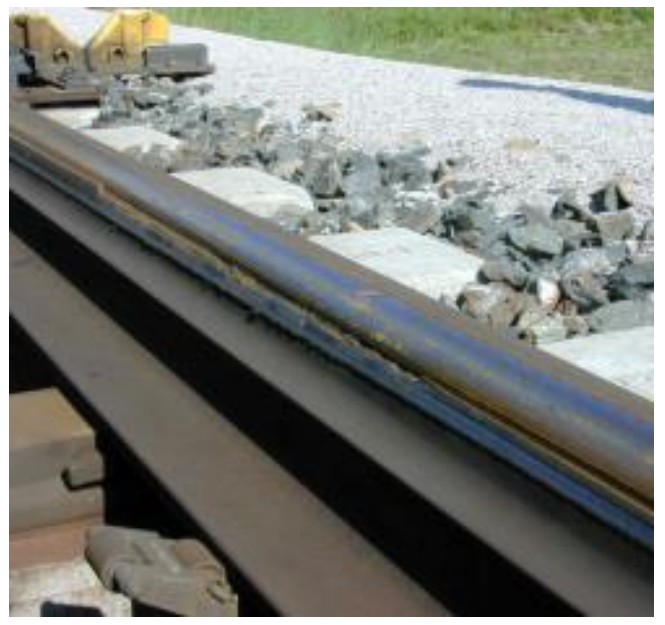

Figure 5: Lipping of the switch blade [3].

\subsection{Crossing panel}

The crossing panel consists of the following main components: crossing nose/vee, check rail, wing rail and tri-metallic weld ends for cast manganese crossings most adopted on the GB network (Figure 1).

\subsubsection{Wear}

Wear on the crossing panel (Figure 6): Excessive wear can appear on the vertical surface of the check rails due to hard flange contact and on the running surfaces such as crossing nose/vee due to a variety of causes, such as excessively stiff bogies with low self-steering properties, excessively narrow check rail gaps, excessive high speeds in diverging direction and accelerating trains in the diverging route. If not corrected, this defect leads to further damage in the crossing area and safety issues due to the gauge corruption. This failure mechanism is generally detected through visual inspection and 
corrected through grinding or replacement of worn components when the wear limits are reached [25]. Preventative measures include the use of lubrication and appropriate rail materials (e.g. heat hardened steels).

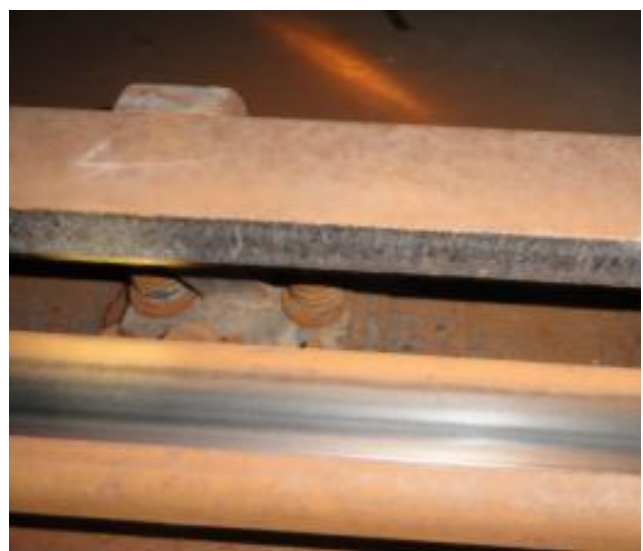

(a)

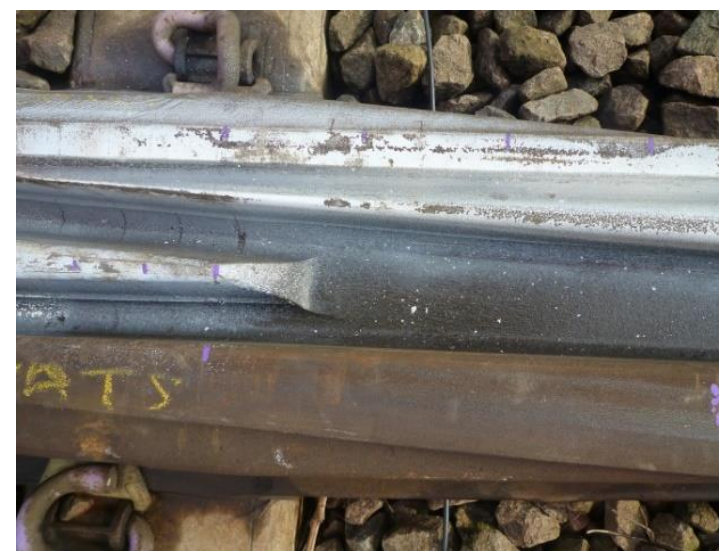

(b)

Figure 6: Wear in (a) check rails [3] and (b) wing rail/crossing nose.

\subsubsection{Fatigue}

Head checks (Figure 7): Head checks are groups of fine surface cracks on the gauge corner of the rail caused by a gross plastic deformation due to wheel/rail contact friction (i.e. ratcheting mechanism). As the cracks are generally close together and are growing at a shallow angle into the rail, they merge underneath the rail surface to cause spalling of small areas. They can result in spalling of material pieces between cracks and in transverse cracks leading to probable rail fracture [26]. This failure mechanism is currently detected through visual inspection, eddy current and ultrasonic testing and requires grinding and/or replacement of the part.

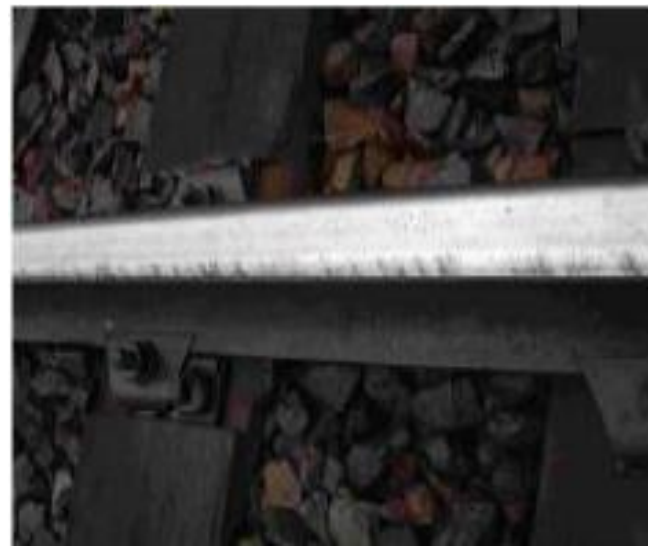

Figure 7: Head checks [3].

Spalling of the crossing (Figure 8): Spalling generally appears in the wheel transfer area and is a result of sub-surface initiation with subsequent merger of fatigue cracks. This defect is caused mainly by high dynamic forces due to non-optimal wheel transfer zone and poor support conditions, wheel flange not matching together with design of wheel transfer zone and inadequate control of wheel profile. It is currently detected through visual inspection. 


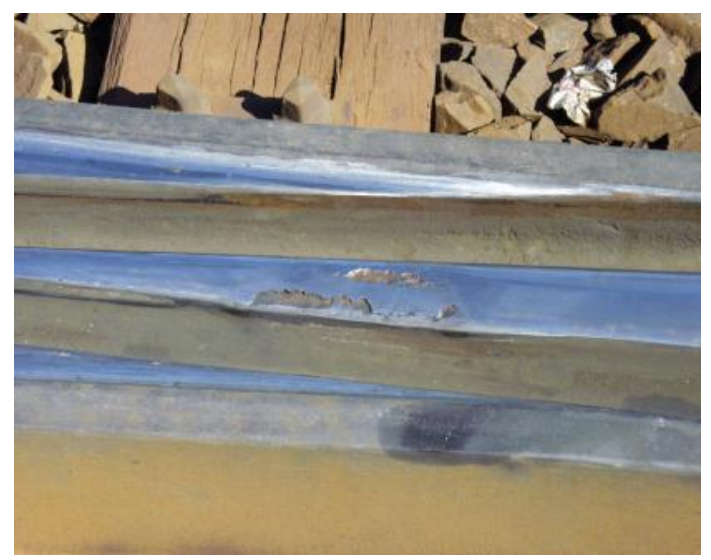

Figure 8: Spalling of the crossing [3].

Cracks on the crossing (Figure 9): The cracks from the base of the crossing are a result of bending fatigue combined with stress-raising effects of machined geometry or surface / subsurface flaws. In the case of Austenitic Manganese Steel (AMS) crossings, leg ends are welded using an intermediate stainless insert and this can lead to hard microstructures that are more susceptible to cracking. Fatigue cracks can appear in the front area of the crossing nose as well as in the rear zone in the crossing. Possible causes can be high dynamic forces, poor support condition, inadequate control of wheel profiles and manufacturing defects, mainly casting porosity.

Transverse cracking in the rail or crossing foot (Figure 9(b)) generally initiates from a corrosion pit or a stress raising geometrical feature and can grow under cyclic loading resulting in a transverse break in the rail. Small corrosion pits are not detectable by current non-destructive test (NDT) techniques. Therefore, this failure mechanism is generally detected through visual inspection and, depending on location of the defect, corrected using weld repair techniques. However, the need for welding expertise and the careful control of temperature required for weld repair of AMS crossings is restrictive and leads to costly replacement. Semi-automatic repair using Flux Cored Arc Welding (FCAW) techniques are now being introduced to undertake such repairs. Further development of crossing repair using milling of the damaged area followed by FCAW is included in the follow-up research project to In2Rail.

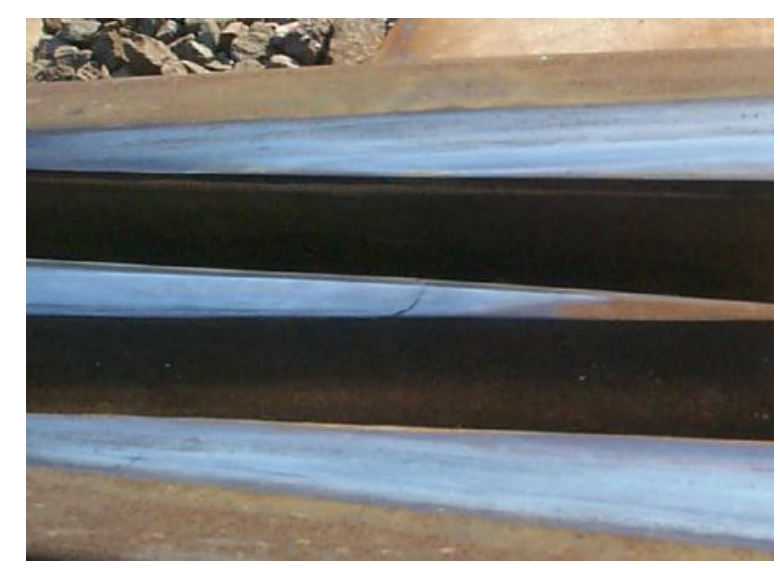

(a)

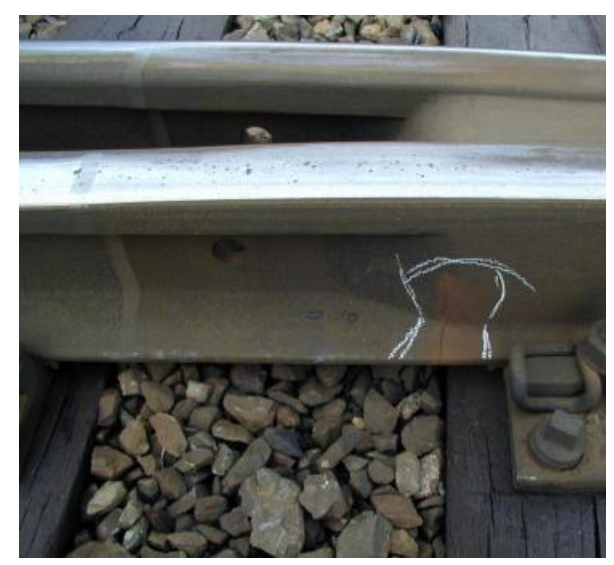

(b)

Figure 9: Transversal cracks (a) on the crossing nose and (b) on the crossing foot [3].

Squats (Figure 10): The squats are caused by RCF defect and appears on the running surface as a localised depression and a dark spot containing cracks with a circular arc or V-shape. The cracks propagate inside the head leading at the end to a rail break or spalling of the running surface in case of 
high-speed turnout. They are often found on flash butt and aluminothermic welds. The main causes of squat formation are not generally well understood, but may include high contact stresses and localised microstructure change due to wheel micro slip. Current methods of detection include visual inspection, ultrasonic testing or magnetic crack detection. Grinding, repair by resurfacing when possible or complete replacement of the rail are among the most typical corrective measures.

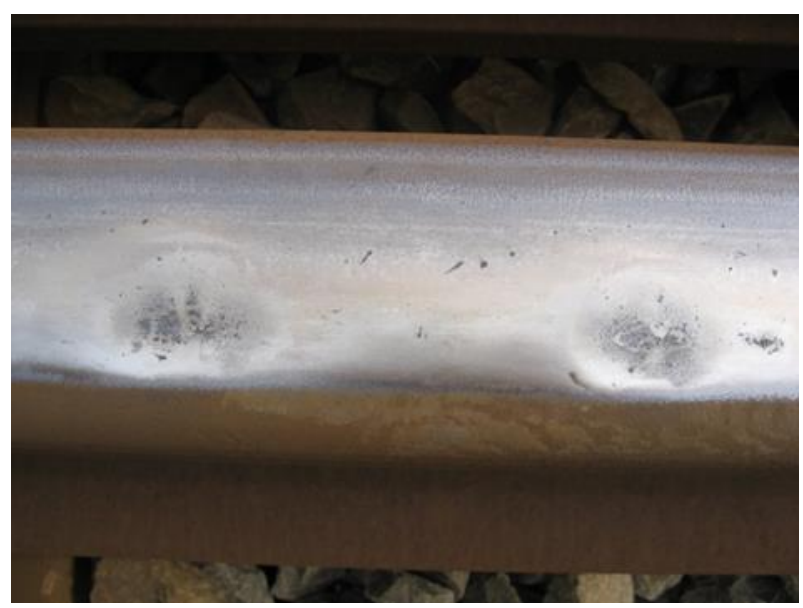

Figure 10: Soft spot in plain line [3].

\subsubsection{Plastic deformation}

Plastic deformation of the crossing nose (Figure 11): Plastic deformations are characterised by yielding of the crossing due to the high lateral contact forces through non-optimal wheel/rail contact surfaces or incorrect geometry. This failure mechanism is generally detected through visual inspection and track geometry checks and corrected through repairs to the crossing nose (i.e. welding, grinding) or full replacement. In the worst cases, a replacement may be needed.

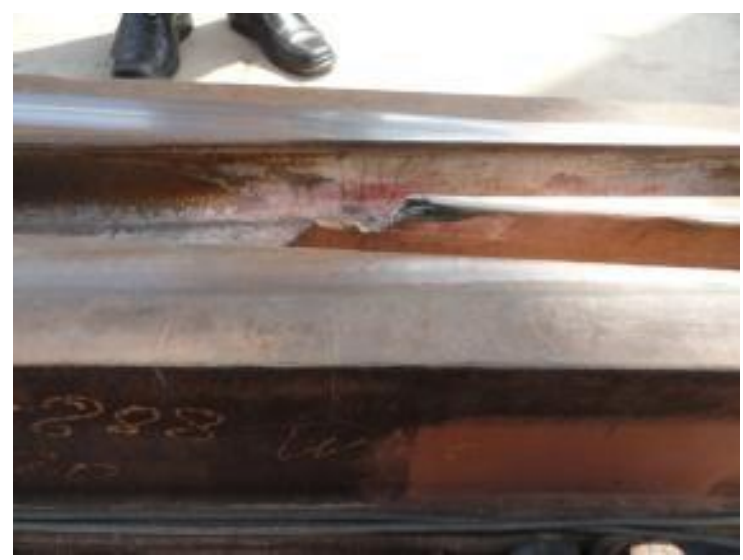

Figure 11: Plastic deformation of the crossing nose [3].

Plastic deformation of the wing rail (Figure 12): This type of plastic deformation is characterised by a depression in the running surface and metal flow leading to the formation of burr on the inner side of the wing rail, material breakouts and spalling of the running surface. Generally, it is caused by the presence of high dynamic forces due to sub-optimal wheel transfer through the crossing or inadequate control of wheel profile shape. It is generally detected through visual inspection and track geometry checks and it is corrected resurfacing with weld build-up techniques or full replacement with alternative hardened materials. 


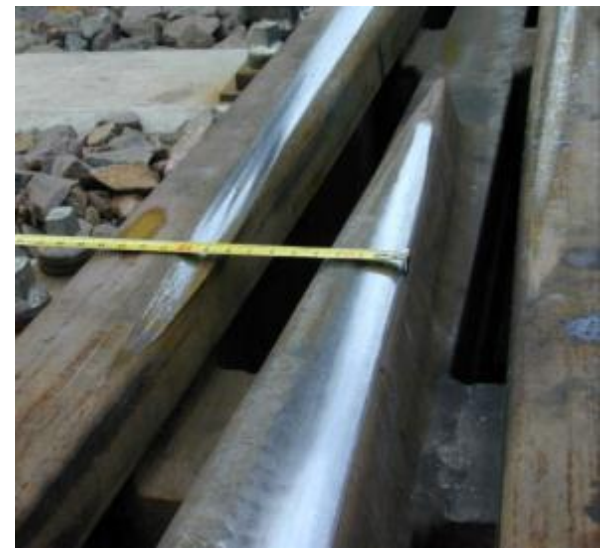

Figure 12: Plastic deformation of the wing rail [3].

\section{Statistical analysis of $\mathrm{S \& C}$ failures}

In this Section, a statistical analysis of the most common failures reported in the Network Rail Rail Defect Management System (RDMS) database for rail level defects in turnouts is presented. The type of data analysed is described in Section 3.1. The classification of failure types based on RDMS data codes is discussed in detail in Section 3.2. Further considerations based on the assembly type, RCF severity, the track category and the steel grade used are commented in Section 3.4. It has to be acknowledged that no information on the traffic type (tonnage, vehicle mix, wheel shapes, etc...) is available in the RDMS database and those aspects are not discussed in this paper.

\subsection{Analysis methodology}

Seven years of GB network RDMS data from 2011 to 2017 has been evaluated in this study. Each failure included in the database has been reported according to several categories, including location (route and site name), type of rail (i.e. left/right rail, S\&C panel), assembly type, track category and track code, rail profile and steel grade.

Each defect is identified using a three digit code. The failures occurring at the switch panel are labelled with 500's codes and the failures occurring at crossing panel with 700's codes. Regarding the failures occurring at both panels, 100's codes refers to failures at rail ends, 200's codes to mid-rail damages, 400's codes to failures at welds and welding repairs, 600's codes to failures at machined rails.

Additional information is included in a comments section of the database in free-text data format. This section provides additional useful information on the reported defect which is not included in other sections of the database. Manual analysis of these records would be time prohibitive and therefore a novel automated text analysis technique has been used to assess this information as described below.

\subsection{Text analysis methodology}

The method applied to extract additional information from the free-text data in the defects database follows the approach developed and used by Hughes [27]. The source data has been loaded into a graphical database with one node for each record. Each record contains 74 fields including data on the name of the site where the defect was found, the date of the inspection and the defect number. The data relevant for this study includes the textual description of the defect and the defect type code that is used to categorise defects. 
A new node has been created in the graphical database for each unique word in the textual description. Each word has been linked in the database to all records where the word occurs. Collocations between words have been indicated by relationship between each pair of adjacent words. The word nodes contain a property indicating how many times the word occurs in the database as well as the relationships between words contained a property indicating the number of times the words occurred as an adjacent pair.

The Term Frequency Inverse Document Frequency (TFIDF) method has been applied to identify words and terms that appeared to be relevant within the corpus. These candidate terms have been presented to the user ranked by decreasing TFIDF value. The user has selected terms relevant to the purpose of the database. For each of the selected terms, new nodes have been created in the database to indicate the terms and their commonly occurring synonyms that would be used during execution of the queries. Expanding on the approach used by Hughes [27], a multi-level ontology of terms has been created containing three types of relationships:

- is a type of: to indicate that one entity described in the ontology is a subclass of another entity in the ontology; for example an star crack is a type of defect;

- is a part of: to indicate that one entity described in the ontology forms part of another entity; for example a vee section is a part of a crossing; and

- is a characteristic of: to indicate that one entity in the ontology is a characteristic or a description of another entity; for example dip angle is a characteristic of a crossing.

The categorisation of terms is shown in Appendix A. It is worth highlighting the fact that the methodology proposed allows to include any further information type (e.g. weather conditions, maintenance record for the track, etc.) which could be used to identify the actions taken to rectify the defects and thus, develop a possible need-based maintenance program.

\subsection{Classification of the failure types}

The percentage occurrence of the 22 most common failure types at S\&C on the GB network between 2011 and 2017 as identified in the database is presented in Figure 13.' 


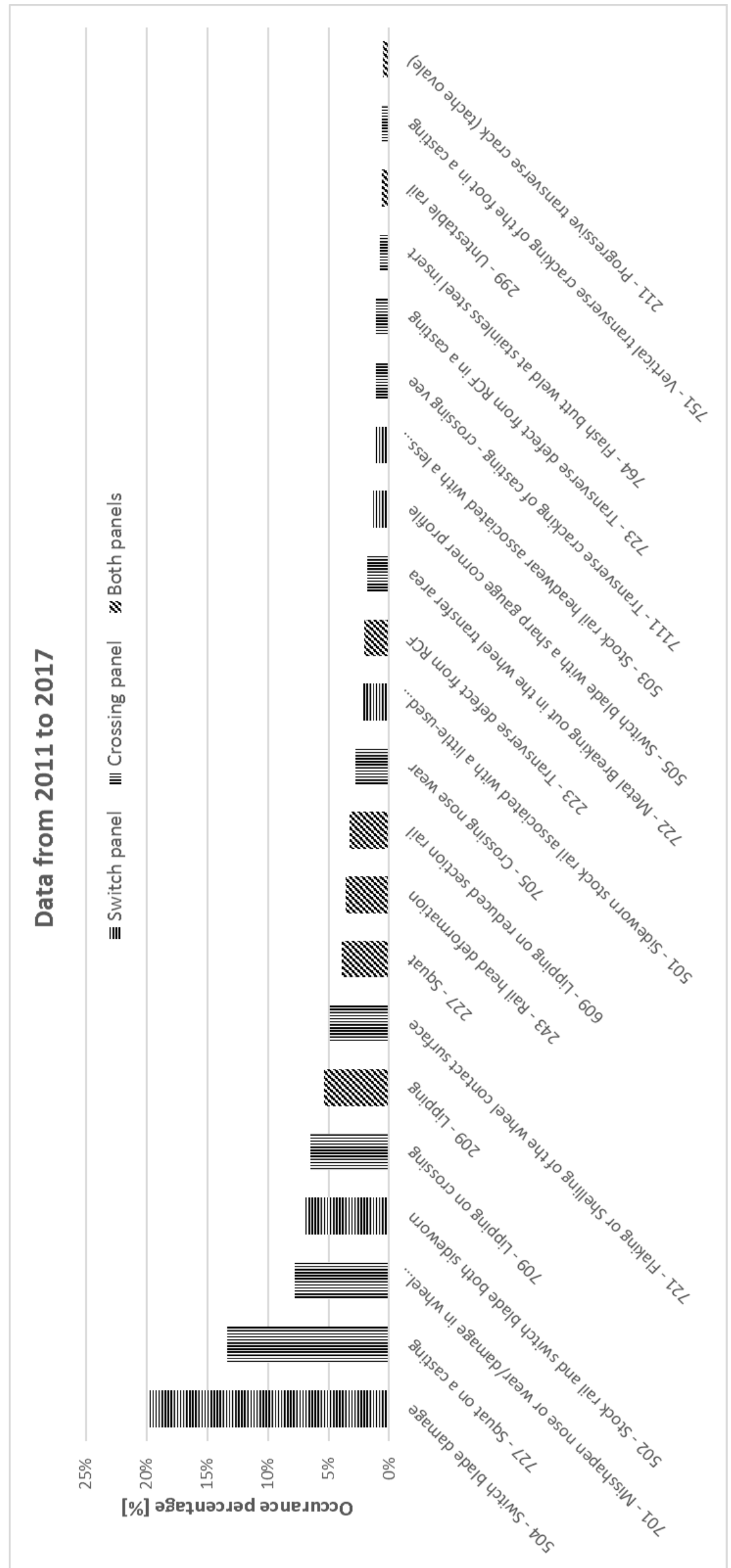

Figure 13: The 22 most common reported failures at S\&Cs in the GB network from 2011 to 2017. 
The data in Figure 13 indicates that most of the identified defects occur on the switch blade (code 504) accounting for approximately $1 / 5$ of all reported failures during the seven years considered. This matches common understanding that the switch blade, characterised by a reduced section, is the weakest component of the system. As a train traverses the switch, high dynamic forces, and thus contact stresses, are almost instantaneously applied to this structurally already weak part of the track contributing to develop damage. Although the need for stronger materials appears an obvious choice, deployment of premium heat treated grades has not been succesful. More recently, Network Rail (NR) introduced their premium grade HP335 in turnout installations but the experience was again considered unsuccessful and the its use has been discontinued. Consequently, it is apparent the loss of structural integrity of the reduced cross section could not be compensated through the use of higher strength steels. However, a low carbon carbide-free bainitic steel has been approved and used successfully by SNCF for fixed crossings. The use of this grade for switch manufacture should also be considered.

Despite the single highest number of failure type being associated with the switch panel and the switch blade, the crossing panel accounts for the highest cumulative number of overall failures, with more than half of the total failures.

Within the codes referring to both panels, it is difficult to distinguish between switch and crossing. Therefore, it would be beneficial to change the reporting methodology introducing specific categories for each panel. As the status quo, it is suggested to introduce a procedure taking into account the comments made by the operators and classify each reported failure consequently.

Additional analysis has been performed in order to distinguish between switch and crossing panel in case of the failure type codes reported as 100's, 200's, 400's and 600's as follows.

On the basis of the database rail profile type entry (Table 1), it has been possible to assign the recorded failures (79\% of the total 100's codes, $73 \%$ of the total 200's codes, $69 \%$ of the total 400's codes and $25 \%$ of the total 600 's codes) to either the switch panel, the crossing panel or left as other.

Table 1: Division between switch and crossing panel based on rail profile type (LH: left-hand; RH: right hand; CWR: continuously welded rail).

\begin{tabular}{c|c|c}
\hline Switch panel & Crossing panel & Others \\
\hline Adjustment switch & Casting apron & CWR \\
\hline LH Lead rail & Casting check rail & Jointed \\
\hline LH Stock rail & Casting leg end & \\
\hline LH Switch rail & Casting nose & \\
\hline RH Lead rail & Casting point rail & \\
\hline RH Stock rail & Casting wing rail & \\
\hline RH Switch rail & Nose in fabricated crossing & \\
\hline Switch Diamond LH & Point rail in fabricated crossing & \\
Switch rail & & \\
\hline Switch Diamond RH & Splice rail in fabricated crossing & \\
Switch rail & Switch Diamond LH Wing rail & \\
\hline & Switch Diamond RH Wing rail & \\
\hline & Vee rail & \\
\hline & Wing rail & \\
\hline & Leg end & \\
\hline & Tri-metal zone & \\
\hline
\end{tabular}

The data that has not been classified based on the rail profile type ( $21 \%$ of the total 100 's codes, 
$27 \%$ of the total 200 's codes, $31 \%$ of the total 400 's codes and $75 \%$ of the total 600 's codes) has been evaluated using the methodology established in Section 3.2 for the free-text analysis.

The percentages of $S \& C$ failure occurrence eventually obtained for each panel are reported in Table 2 . This significantly reduces the number of un-associated failures from $26 \%$ (one quarter) to $3 \%$ (marginal), and highlights that more than half the reported damage is associated with the crossing panel, with $53 \%$ as opposed to $44 \%$ for the switch panel.

Table 2: Percentage $S \& C$ failure occurrence at each panel using only the database or using database and freetext analysis.

\begin{tabular}{l|l|l}
\hline & \multicolumn{1}{|c|}{ Database } & \multicolumn{1}{c}{$\begin{array}{c}\text { Database and free- } \\
\text { text analysis }\end{array}$} \\
\hline Switch panel & $32 \%$ & $44 \%$ \\
\hline Crossing panel & $42 \%$ & $53 \%$ \\
\hline Other & $26 \%$ & $3 \%$ \\
\hline
\end{tabular}

\subsubsection{Damages occurring only at switch panel}

The percentage occurrence of the most commonly observed failures occurring at the switch panel is shown in Figure 14.

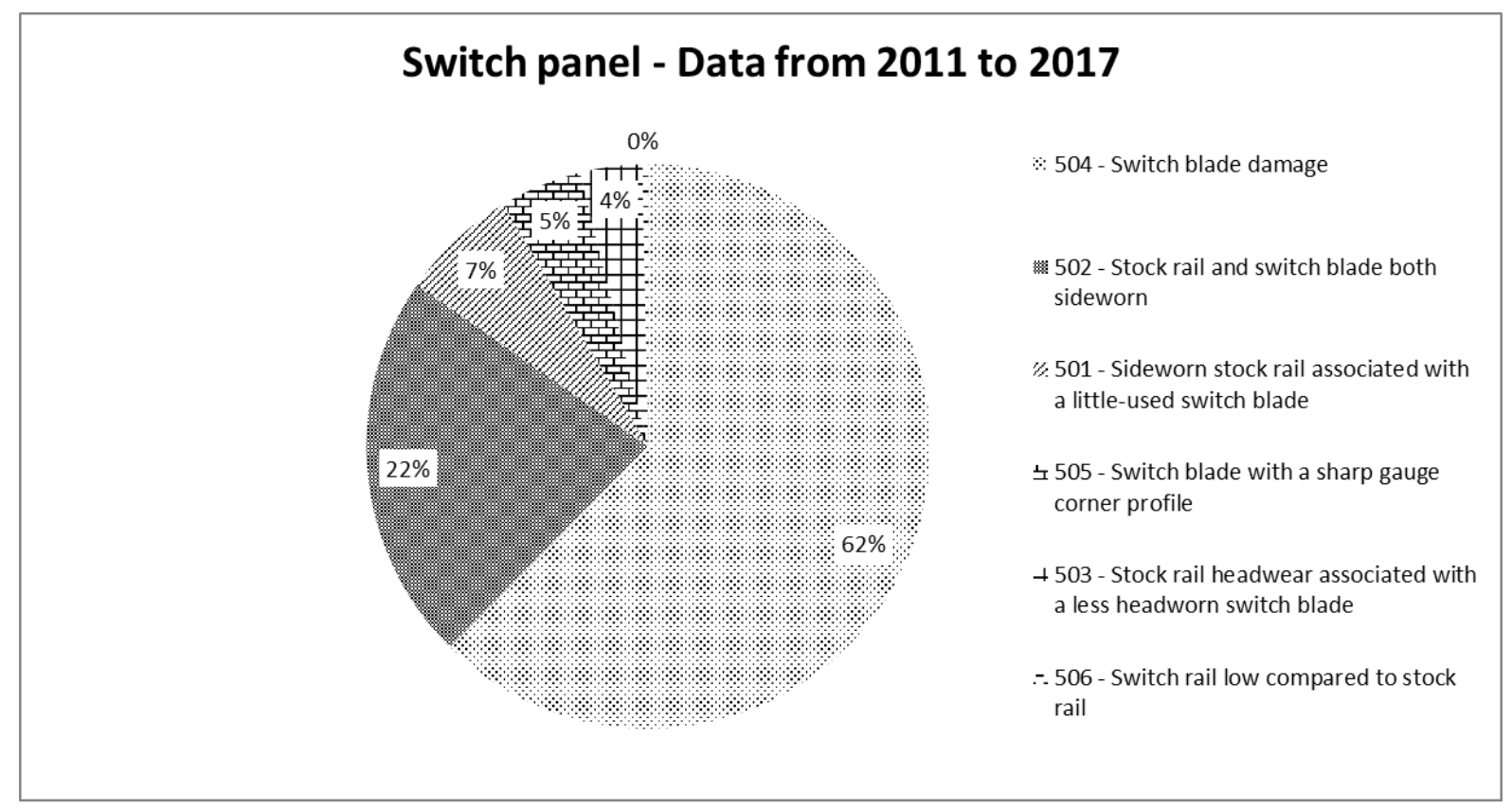

Figure 14: Reported failures at the switch panel in the GB network from 2011 to 2017.

As anticipated in Figure 13, Figure 14 confirms that the switch blade damage is the most common damage occurring at the switch panel, representing approximately $2 / 3$ of the total failure occurrences. The results from the text analysis show that almost half of the entries (i.e. 47\%) refers to "lipping" as the damage mode. Cracks or breaks have a lower occurrence rate, which is $7 \%$ and 5\% respectively, however they might more severely affect running services and accrue to higher delay costs. The RCF mechanism, instead, has a very low occurrence rate $(0.5 \%)$.

The second most common damage mechanism is the coexisting wear of stock and switch rail ( $22 \%$ of the total reports). It is about 3 times more frequent than the case of wear only occurring at the stock rail. Although materials with higher resistance to wear (higher hardness steels) are available, this needs to be balanced against the risk of RCF crack growth and reduced ductility. This aspect is further 
discussed in the recommendation section.

Records with reports of failures with a sharp gauge corner profile have a low occurrence rate of approximately $5 \%$.

In order to understand a possible relationship between the lipping phenomenon and the wear mechanisms, the free-text analysis has been applied to the three most common failures at switch panel (i.e. codes 501, 502 and 504) searching for the word "lipping" (Figure 15). Three types of traffic directions, which are up, down and bi-directional, and three types of track types, which are fast, slow and freight, have been considered ${ }^{2}$.

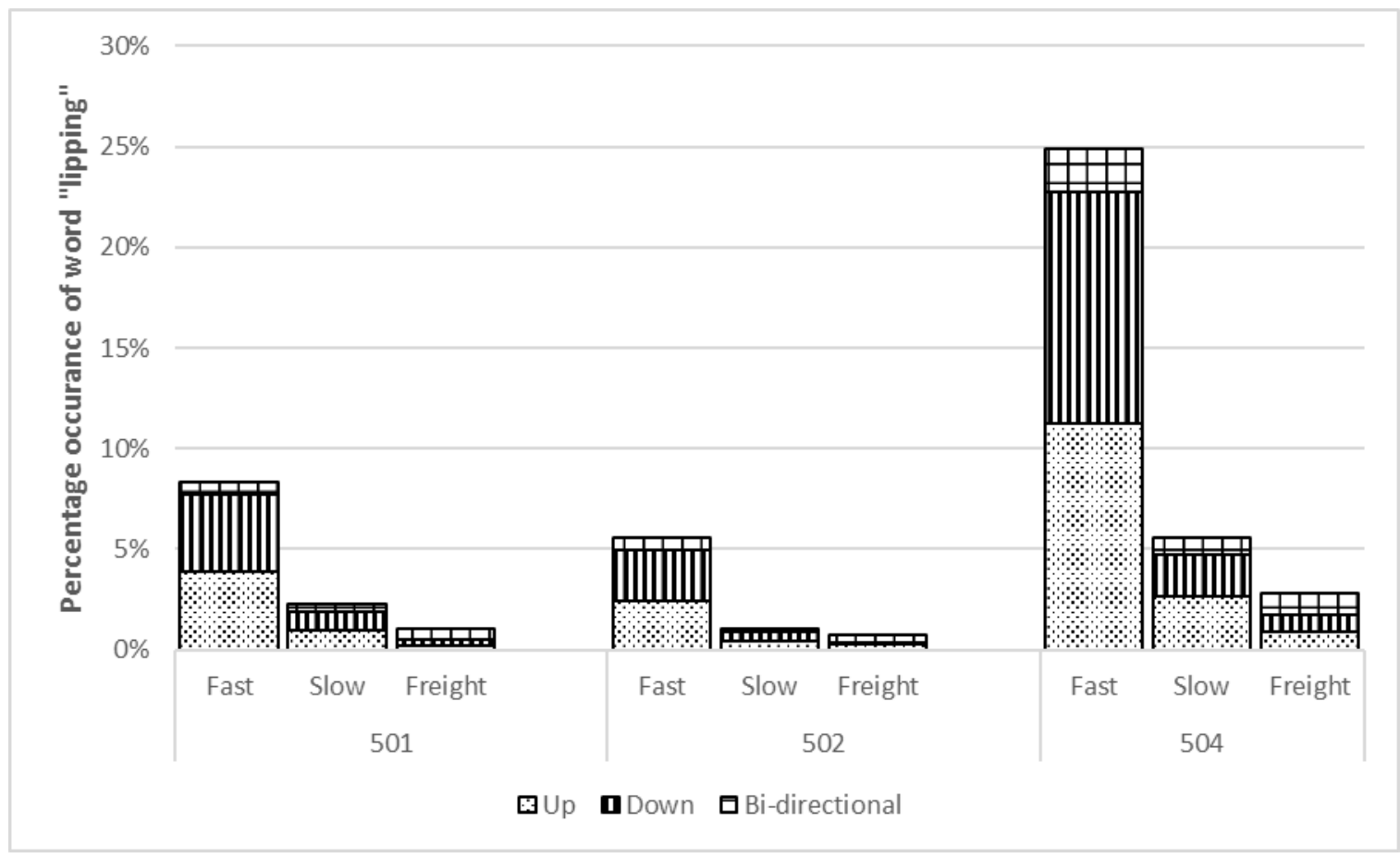

Figure 15: Percentage occurrence of the word "lipping" in the three most common damage mechanism at switch panel.

Code 501 refers to cases in which the most used direction is the through route with substantial cant deficiency, i.e. in a curved track [28]. This failure mode in association with lipping is mainly linked with the up and down directional traffic on the fast lines. Similar conclusions can be drawn for the code 502 and 504. Overall, code 504 shows highest percentage occurrence of the word lipping in the free text report, highlighting the fact that lipping is highly associated with general switch blade damage reporting especially on fast lines $(25 \%)$.

\subsubsection{Damages occurring only at crossing panel}

The percentage occurrence of the most commonly observed failures occurring at the crossing panel is presented in Figure 16.

${ }^{2}$ In the RDMS database, the track type refers to the Track ID (TID) code in the form DNXX, where D represents the normal direction (1: up; 2: down; 3: bi-directional; 4: merry go round loop) and $\mathrm{N}$ the track name (1: fast; 2: relief, slow or through; 3: freight; 4: single line; 5: loop; 6: terminal track or bay line; 7: crossover; 8: other; 9: siding). 


\section{Crossing panel - Data from 2011 to 2017}

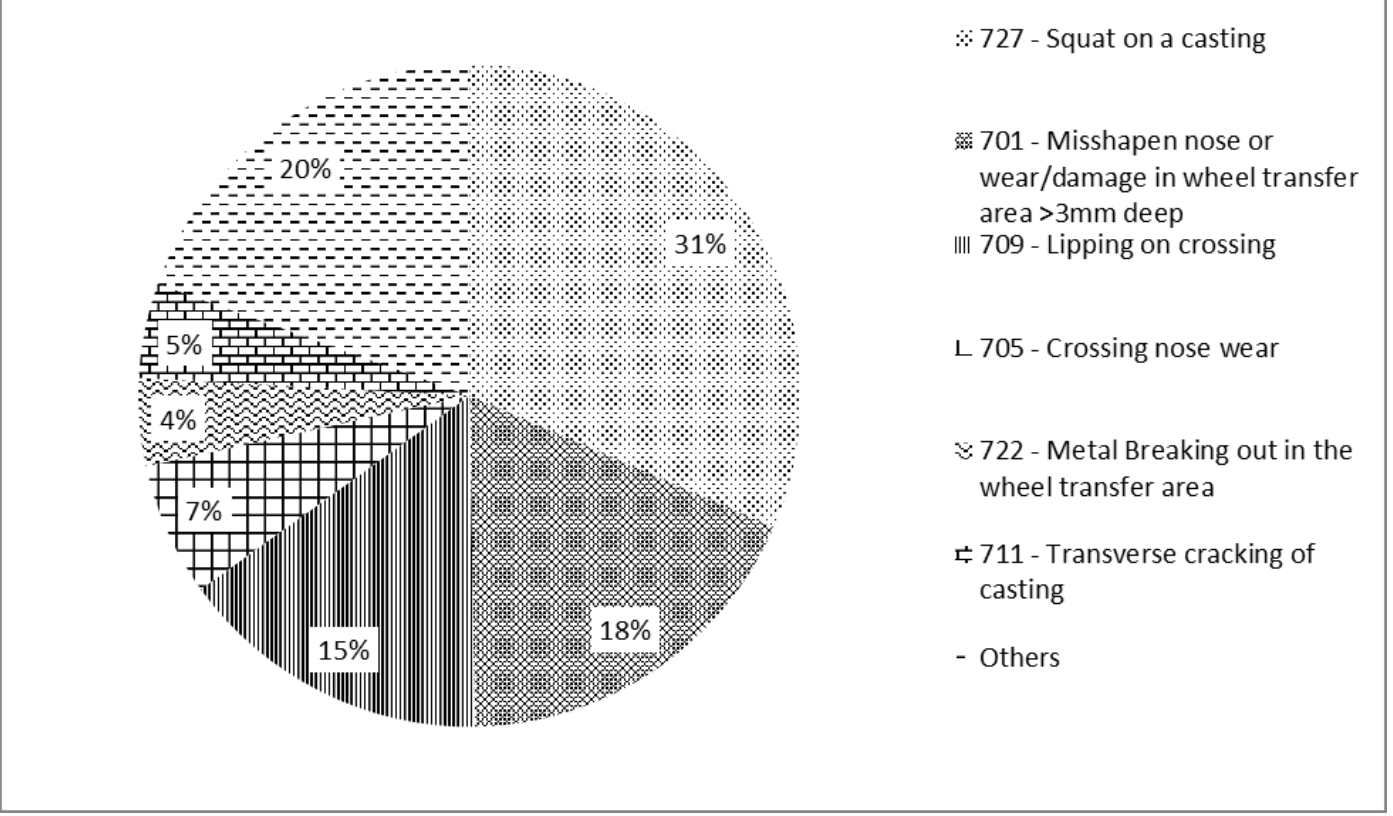

Figure 16: Reported failures at the crossing panel in the GB network from 2011 to 2017.

Although the database results suggest 19 types of failures within the crossing panel, $80 \%$ of the failures are accounted for by just 6 failure types (Figure 16). In contrast, 5 failure types account for virtually all failures within the switch panel.

The most common cause of failure at the crossing panel is reported as squat on a casting, representing approximately $1 / 3$ of all the turnout failures, and the second largest defect category (Figure 13). The data analysis combined with the text analysis has shown that the most common location of defects is the nose ( $46 \%$ of the total occurrence), followed by the leg end (10\%) and the wing rail $(10 \%)$. In $34 \%$ of cases it is not possible to conclude the location from the text analysis, since the location was either not specific, or was written in a way that was not detected by the analysis. High wheel-crossing contact stresses are the primary source of degradation, particularly at the crossing nose and wing rail. These stresses can be amplified by a wide range of factors, including non-optimal profiles, incorrect installation and insufficient maintenance [3]. These types of faults can be exacerbated by the presence of sub-surface flaws that are more prevalent in castings compared to rolled rails used in fabricated crossings. This finding is confirmed by the data analysis which shows that $41 \%$ of the squat failures occur in cast crossing, $4 \%$ in fabricated crossing, while 55\% is unspecified. Unfortunately, the text analysis has not resulted in any additional useful information.

RCF mechanisms, such as squats and shelling, represent half of all the failure occurrences, while plastic deformation $1 / 3$ and wear mechanisms $1 / 4$.

A text analysis has been carried out on two failure codes, i.e. code 701 ("misshapen nose") and code 709 ("lipping"). Figure 17 shows the correlation of the relative occurrence of specific words in relation to each types of reported defect. From Figure 17(a) it is possible to see that there are relatively few of the word searched for relating to either defects as most of the data points are centred around the origin, with the exception of one or two points. These are:

- 'wear' which is commonly associated with the misshapen nose (code 701), but not with lipping (code 709); and 
- lipping is as expected highly correlated with lipping (code 709) and not commonly associated with misshapen nose (code 701).

Removing these points, it is possible to focus on the term with relatively low occurrences (i.e. less than $8 \%$ for code 701 and less than $2 \%$ for code 709). Around the origin (Figure 17(b)), there is similar occurrence rate of each highlighted terms with each defect codes. In particular, 'shelling' is equally relevant for misshapen nose and lipping. The term "break" is slightly more relevant for misshapen nose as this can eventually lead to breakage of material on the nose, while 'squats', 'crack' and 'RCF' are slightly more relevant for lipping as lipping can eventually leads to or resemble cracks generate by squats and RCF. In all cases, a misshapen nose is likely caused by combined high vertical impact forces with large lateral offset of the axle towards the crossing, in combination with early load transfer in on the nose where its width is too small to structurally withstand the load. Finally, lipping is associated with high lateral creep forces.

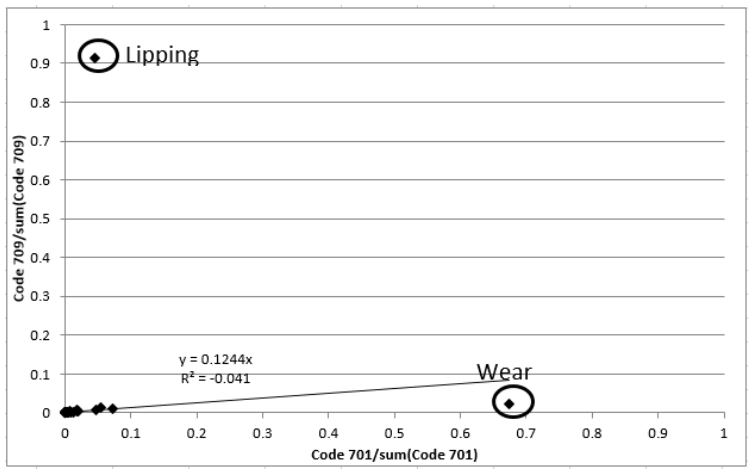

(a)

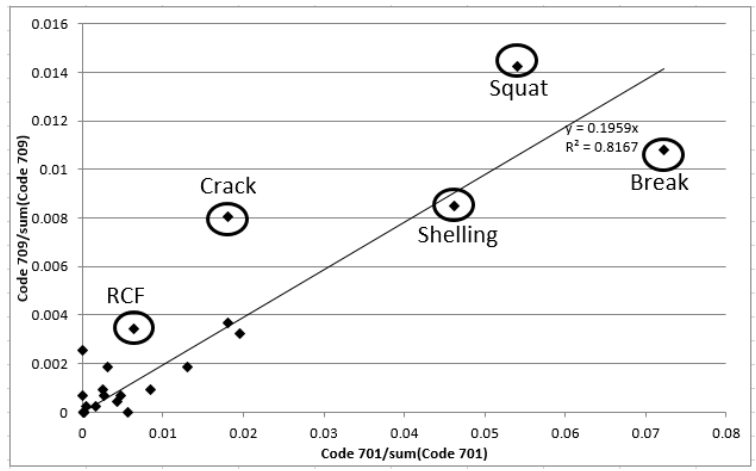

(b)

Figure 17: Relationship between misshapen nose and lipping percentage occurrence (a) including the outliers and $(b)$ excluding the outliers.

The transversal cracking of casting (code 711) is caused by the exceedance of total stress over the material yield threshold and usually occurs in the proximity of stress raisers, such as tri-metallic welds, near the wheel/rail impact location within the wheel transfer area or the wing rail. Its occurrence is about $5 \%$ of all the failure mechanisms ( $2.6 \%$ occurring at the casting vee, $1 \%$ at the wing rail, $0.6 \%$ at the leg end and $0.4 \%$ elsewhere). Nevertheless, this failure mode is one of the most expensive for the railway in terms of delays and track possession costs if not detected and prevented. In fact, once the cast is cracked it needs to be immediately substituted as it is not possible to weld repair it if in cast manganese or if the cracks are not superficial.

\subsubsection{Damage types occurring on both panels}

The relative occurrence of the most commonly observed failures occurring at both panels is shown in Figure 18. 


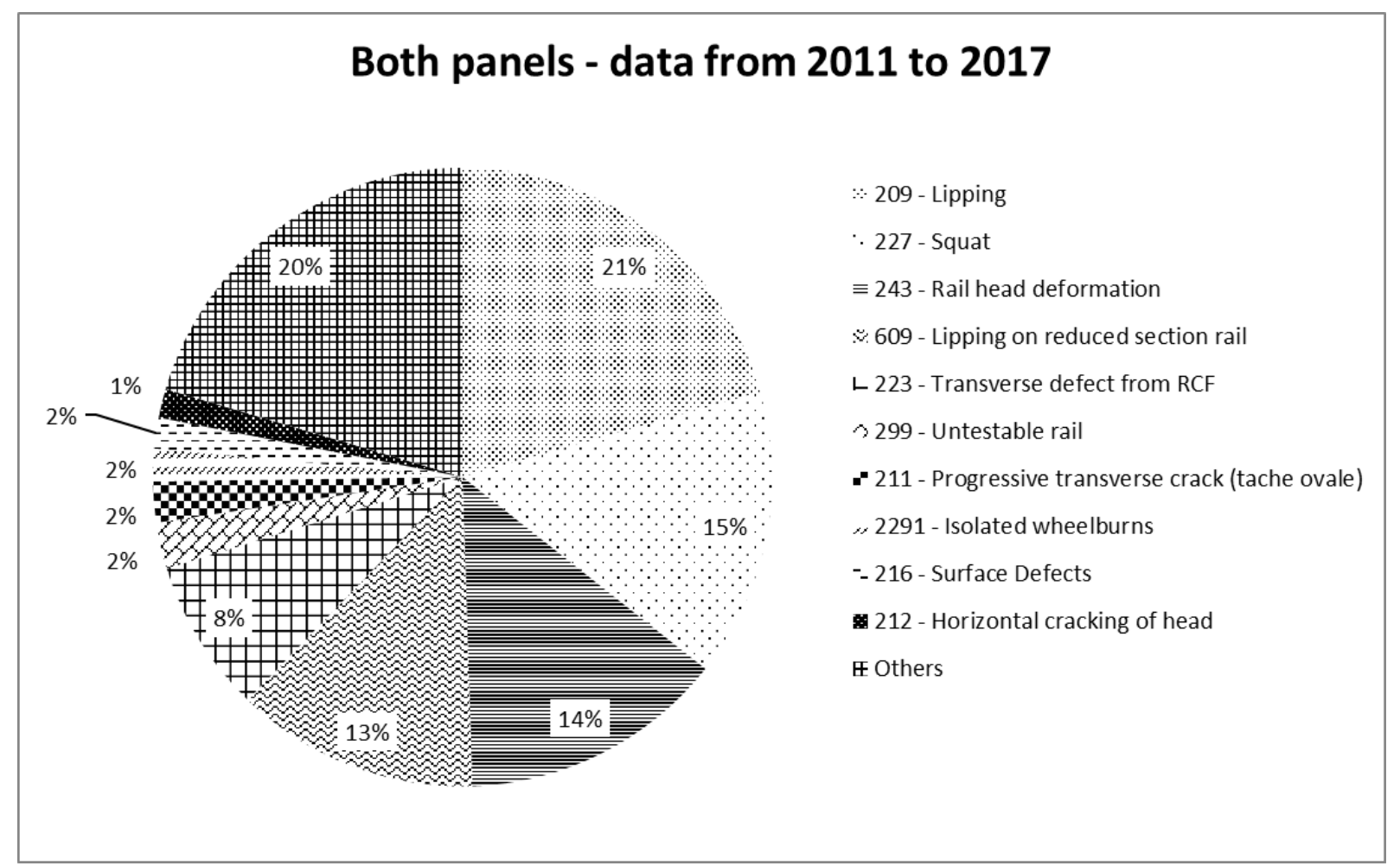

Figure 18: Reported failures occurring at both panels in the GB network from 2011 to 2017.

Figure 19 shows the occurrence percentage of the observed failures divided accordingly to code groups and Figure 20 the most commonly observed failures per each code group.

\section{Both panels - data from 2011 to 2017}

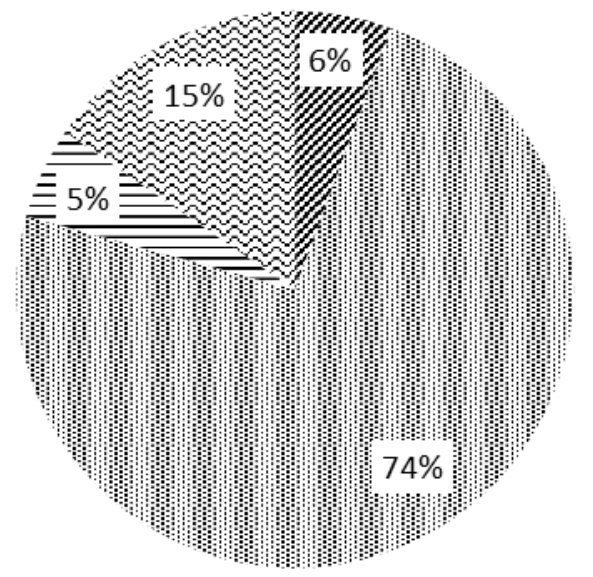

Z Rail ends (codes 100s)

Mid rails (codes 200s)

$=$ Welds and welding repairs (codes 400s)

$\because$ Machined rails (codes 600s)

Figure 19: Groups of reported failures occurring at both panels in the GB network from 2011 to 2017. 


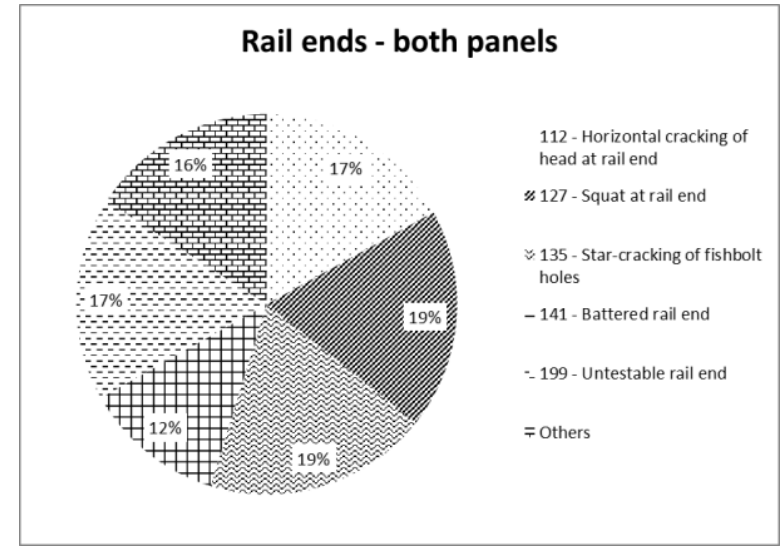

(a)

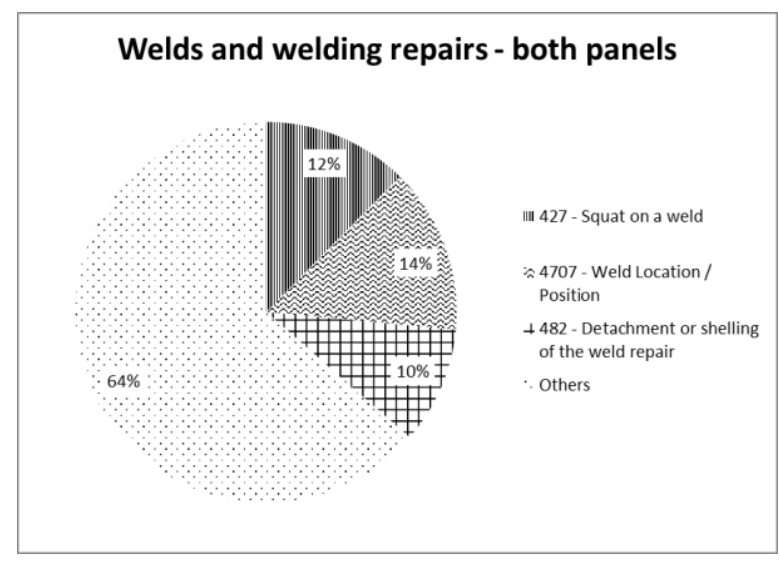

(c)

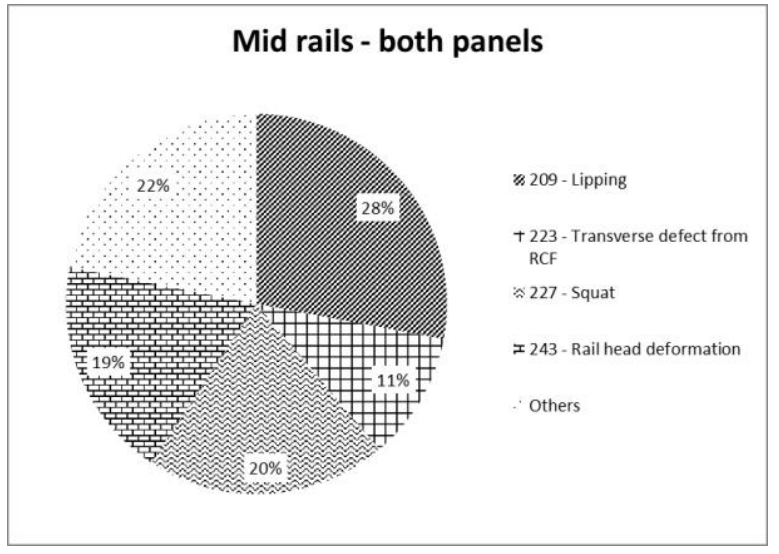

(b)

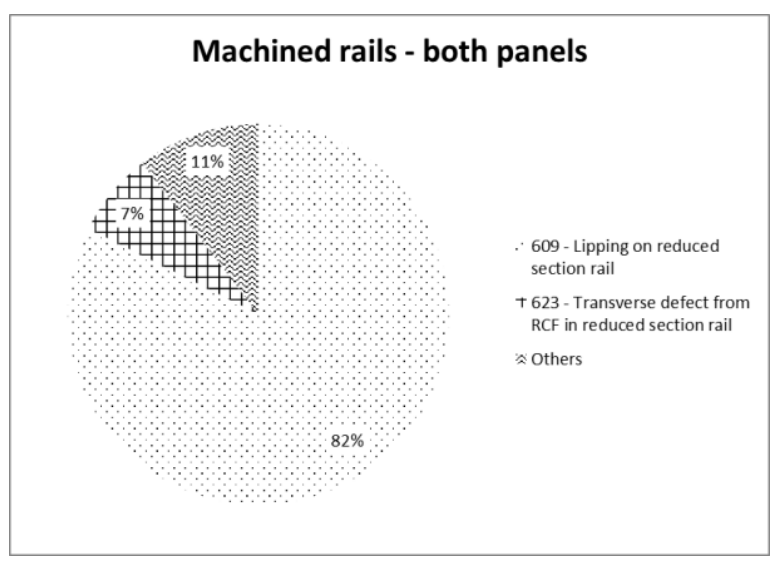

(d)

Figure 20: Most common reported failures depending on the main group types occurring at both panels ((a): rail ends; $(b)$ : mid rails; $(c)$ : welds and welding repairs; $(d)$ : machined rails).

From Figure 18 it is possible to deduce that the most common cause of failure at the both panels is lipping, representing approximately 1/5 of all the failures. Defect 209 (lipping), defect 243 (rail head deformation) and defect 609 (lipping on reduced rail section) represent approximately $48 \%$ of the total failures occurring in both panels. This fact clearly shows a need for high yield strength materials.

Four main groups of observed failures are considered (see the failure codes in RDMS data, Figure 19 and Figure 20):

- Mid rails (74\% of the total failures at both panels as in Figure 19):

As surface damage is the most prevalent damage mechanism, optimisation of contact conditions and the use of degradation resistant materials at the interface should be the focus of any future research. In particular, plastic deformation and RCF mechanisms seem to be the more prevalent ones, reaching 55\% and $40 \%$, respectively. Wear mechanisms play a minor role, as it causes up to $2 \%$ of the total surface failures at most, as crossings are replaced prematurely because of plastic deformation and RCF related failures before wear limit is reached.

- Machined rails (15\% of the total failures at both panels as in Figure 19):

"Reduced section rail" refers to the machined parts of the S\&C panels, such as switch rail, wing rail, check rail, etc... As expected, plastic deformations and RCF mechanisms reaches up to $90 \%$ of the total failure modes in the reduced section rails.

- Rail ends (6\% of the total failures at both panels as in Figure 19): 
The RCF mechanisms at the rail end are the dominant failure causes of fish blade joints, reaching $41 \%$, followed by failures of the fishbolt holes (up to 25\%) and battered rail ends (up to 12\%).

- Welds and welding repairs (5\% of the total failures at both panels as in Figure 19):

There are a large variety of failure mechanisms occurring at weld location, which are mainly linked with the process used (such as aluminothermic/flash-butt/arc welding process [29]) and the relative position of the two parent rails (specific standards, as in [30,31], have been issued to avoid this problem). Unfortunately, it is not possible to separate between failures at or near tri-metal welds joining rails with legs of cast crossings as such welds remain a welding challenge.

\subsection{Other considerations}

Data related to the type of assembly, material and the track type has been also analysed. As expected, most of the failures occur in the common assemblies (up to 90\%), while 5\% occurs in obtuse crossings which are far less numerous. Regarding the material type, it is unknown for almost half of the entries (47\%) and, thus, this type of analysis is inconclusive. The track category seems to influence the failures. More than half of them occurs in the fastest lines (cat 1A/1/2 refers to line speeds of $120 \mathrm{~km} / \mathrm{h}$ and above [32]), presumably because they are also the most heavily used but also because dynamics loadings effect become more dominant at higher speeds.

Finally, using the text analysis, it has been possible to extract the support failure occurring at the infrastructure level. The findings are summarised in Table 3.

Table 3: Failure at the support based on text analysis.

\begin{tabular}{l|l|l|l|l|l}
\hline $\begin{array}{c}\text { Infrastructure } \\
\text { part }\end{array}$ & $\begin{array}{c}\text { N. } \\
\text { records } \\
\text { found }\end{array}$ & $\begin{array}{c}\text { Switch } \\
\text { panel }\end{array}$ & $\begin{array}{c}\text { Crossing } \\
\text { panel }\end{array}$ & Others & \multicolumn{1}{c}{ Comments } \\
\hline $\begin{array}{l}\text { Support } \\
\text { (voids) }\end{array}$ & 346 & $21 \%$ & $64 \%$ & $15 \%$ & $\begin{array}{l}\text { - Switch: switch blade damage (24\%) } \\
\text { - Crossing: Squat (17\%), lipping (17\%), } \\
\text { misshapen nose (14\%), transverse } \\
\text { cracking (10\%) }\end{array}$ \\
\hline
\end{tabular}

Table 3 shows that the majority of occurrences are associated with the crossing panel and with failure types such as squat, plastic deformations and transverse cracking. This is in line with the expectations, as explained in Section 3.3.2.

\section{Mitigation of observed failure types}

In this section, the main conclusions drawn from the failure analysis are linked to existing research to identify potential solutions for mitigation of observed failures. Areas for further research are highlighted for the switch panel (Section 4.1), the crossing panel (Section 4.2) and for general reporting methods (section Error! Reference source not found.).

\subsection{Switch panel}

The presented failure analysis of switches has shown damage switch rails and side worn switch and stock rail to be dominant mechanisms. Consequently, research on material improvement would be very beneficial to overcome wear damages, especially to give suggestions on the manufacture of switch blades or even switch stock assembly from steel substrate clad about the "optimum" degradation resistant materials. 
A Shift2Rail project In2Track deliverable [33], describes the researches that have been undertaken across Europe in the past few years, such as the comparison between the steel grades R350HT and R260 in switch blades and stock rails under suburban passenger traffic for the purpose of solving the wear and flaking problems and the comparison between the steel grades B360 and R260 in curved switch blades and stock rails under suburban passenger traffic for the purpose of solving the RCF and severe head checking problems. While in-situ testing gives confidence in the applicability of certain steel solutions, accelerated laboratory testing remain a safer and faster way to appreciate the benefit of a wide range of material solution and it recommended that testing facilities be developed to capture the specific load conditions seen in switches components.

Recent work in European funded Shift2Rail projects, have engaged in two distinctive paths to deliver reliable and resilient switches [34]:

- Enhancement to the existing technology:

In some European countries, such as Sweden, UK and Germany, thick switch blades have been introduced so that the load transfer area between stock and switch rail happens where the blade is stronger to resist the impact loadings and more tolerant of wear. Improved load transfer reduces wear as well as the probability of broken tips. Voestalpine [35] proposed an optimised switch profile (TOZ) which is characterised by additional thickness of the switch blade in the most critical area, leading to a prolonged service life.

In connection to the above, kinematic gauge widening (KGO) is in place in order to improve steering and lower lateral impact on the blade at the load transfer area (see for example [36-38]). In this way, it is possible to decrease observed failures such as wear and lipping, which represent more than half of the reported failures.

- Innovative solution, stepping away from current switch mechanisms:

A number of innovative solution are emerging with an attempt to remove the weakest component, i.e. the switch rails. An innovative hopping switch actuator contained in a multi-channel actuation bank has been proposed by Bemment [39], in which a passive locking is used and only lifting the rail allows disengaging the devices and moving them laterally. Redundancy is given by the fact that the units adjacent to an isolated actuator can still actuate the switch. The wheel-rail interaction has been investigated in [39], highlighting further work required in the design of the stub switch joint.

In the project In2Rail, flange-back steering (FBS) has been proposed (Foan [40]), which removes the needs for a thin switch blade by separating the load carrying function of the wheel from the guidance using the back of the wheel and contacting steering elements in the track. The wheel-rail interaction problem has been analysed in Bezin [41]. Modularity is expected to be used with consequent reduction in maintenance costs. However, significant challenges are introduced, including the definition and evaluation of the correct material and component requirements that enables flange-back steering, the fine tuning of optimum load transfer at the knee and the careful design of steering operating mechanism concepts.

Moving away from track-based mechanisms to vehicle-based mechanisms, active steering that relies on steered axle or independently driven wheels to switch path is another area of increased interest for the future research thanks to the availability of improved control system technology and modelling tools. Completely passive crossing layout leads to a reduction in complexity from the track side and, thus, a possibly substantial reduction in observed failures, while an increase is expected in the active actuating elements and the associated control system on-board vehicles. 


\subsection{Crossing panel}

The major issues identified are squats, shelling, plastic deformation and wear mechanisms, resulting from non-optimal wheel-rail interaction and inadequacy of material to resist high dynamics loads. Even if the material aspects are usually acknowledged as crucial, it is believed that the major contribution toward reducing the particular squat failure can be achieved from a reduction in the wheel/rail impact loading by optimising the contact surface of crossing to comply with current trafficked wheel shapes, as well as mitigating the effect of the impact load with improved support stiffness below the superstructure and better load distribution capabilities from the track superstructure design (see for example [36, 42-45]).

Regarding the plastic deformation, it is highly relevant to better understand the dependence on yield strength of materials, looking for instance to the metallographic assessment of the plastic flow at different key cross sections of the casting, relating it back to service loads.

\subsection{Reporting methodology}

The free text analysis presented in this paper show the importance of increasing the quality and consistency of free text reporting, to enable additional intelligence to be gained on the specific details of the damage types reported within more generic code categories (see for e.g. code 504 analysis in section 3.3.1). However, the method applied in this analysis uses an ontology of defined terms for identifying specific types of defects, which relies on the terms used in the records matching the terms defined in the ontology. Where different descriptions or variations in spelling are used (e.g. if the spelling variation spaling is used instead of spalling) then these records will not be included in the statistical analysis.

For a database where all records are related to a single type of event (in this case, track defects) it is practicable to detect all spelling variations due to the relative small number of different words that occur in the database. For databases that contain a larger number of distinct words, for example databases that describe all types of infrastructure defects as well as rolling stock defects, or for very large databases (millions or even billions of records) then it is not practicable to detect all spelling variations. For these cases other techniques could be employed to detect spelling variations for example by using Levenshtein distance (see Schulz and Mihoy [46]) or Soundex encodings to identify spelling variations that are phonetically similar to each other. Terms identified in this way could be added to the ontology.

The method of using ontologies to analyse text could potentially be applied for many other types of railway data including data on operational incidents and even public and passenger safety as used by Hughes [27]. To do so would involve expanding the ontology to include the terms relevant to these other types of event. Extending the ontology in this way is, however, labour-intensive: currently there are no known methods that are effective at creating meaningful ontologies without human intervention (see van Gulijk et. al [47].

\section{Conclusions}

In this paper, the most frequently observed failures at the switch and crossing panels are identified and discussed, along with possible causes and mitigation measures are summarised. Seven years of rail defect data from the GB network has been evaluated statistically with the support of free-text analysis 
techniques to capture extra information from the manual entries. The conclusions detailed in the following paragraphs are supported by the evidence provided in this paper and only relate to the results of the statistical analysis. While the other general conclusions are provided on the basis of the literature available and knowledge of the authors.

One of the main conclusion from the work is that both the crossing and switch panels suffer a high rate of failures and damage with a slightly higher proportion on the crossing panel. Approximately $1 / 5$ of all the registered failures during the 7 years considered relate to switch blade damage. The key driver for most failures are amplification of already high dynamic forces and huge contact stresses, applied to structurally weak components (switch and nose) of the track.

Regarding the switch panel, the free-text analysis showed that almost half of the entries (i.e. 47\%) related to switch blade damage refers to lipping damage mechanism, while cracks or breaks have a lower occurrence rate, at $7 \%$ and $5 \%$ respectively. The second most common damage mechanism is the coexisting wear of stock and switch rail (approximately $1 / 4$ of the total reports).

Regarding the crossing panel, $80 \%$ of the failures are accounted for by just six failure types. The most common cause of failure at the crossing panel is squat on a casting, representing approximately $1 / 3$ of all the turnout failures, and the second largest defect category. The data analysis and the text analysis has shown that the most common occurring location is the nose (46\% of the total occurrence), followed by the leg end $(10 \%)$ and the wing rail (10\%). The analysis implies that most issues are with common crossings used in facing direction. High contact stresses resulting from wheel-crossing contact is the primary source of degradation, the severity of these stresses is amplified by non-optimal profiles, incorrect installation and insufficient maintenance. They can be further exacerbated by the presence of sub-surface flaws that are more prevalent in castings compared to rolled rails used in fabricated crossings. Leg end design is also in need of improvement with non-negligible failure rate.

Regarding the failures occurring in both panels, the most common cause of failure at both panels is lipping, representing approximately $48 \%$ of the total. This indicates the action of high lateral creep forces alongside high normal loads, which need to be improved by better design of vehicle steering and wheel-rail guidance in turnouts. Surface damage is the most prevalent damage category, especially plastic deformation and RCF mechanisms.

Recommendations for future research based on the above highlight the following. In the switch panel, it is recommended to investigate methods to improve steering and move load transfer away from the thin switch blades. Despite the fact that radical options proposed so far are potentially introducing new and different damage mechanisms, it remains a plausible avenue to be researched since the current switching principles have not changed in over 150 years. Research on material resistance to combined normal and shear stresses is essential to deal with wear, fatigue and plastic deformation. This might take the form of new alloys with current rolled steel capabilities or take advantages of new cladding deposited technologies.

In the crossing, the materials are subject to particularly high stresses. A major improvement would come from a reduction in the wheel/rail impact loading by optimising the contacting surface of the crossing and its compliance with wheels, as well as the improving the support stiffness. Regarding plastic deformation, it is suggested to better understand the dependence of materials on yield strength, looking to the metallographic assessment of the plastic flow at different key crossing sections. Moreover, even if the transversal cracking of casting caused by the exceedance of total stress over the material yield threshold has a low occurrence rate, this failure mode represents one of the most expensive ones in terms of delay minutes.

The free-text methodology proposed in this paper provides the opportunity to include further 
information (e.g. weather conditions, maintenance record for the track, etc.), which could be used to identify the actions taken to rectify the defects and, thus, be used to support a failure-based maintenance approach.

Finally, as a general consideration, a high proportion of failure modes were seen to be classified with codes referring to both panels. Since it is difficult to distinguish between switch and crossing, it would be beneficial to change the reporting methodology introducing for example, illustrative examples and a tick list leading the operator to the correct classification.

\section{Acknowledgement}

This work was partially supported by the EPRSC project Track to the Future (grant agreement No. EP/M025276/1). The support from Network Rail in this project is gratefully acknowledged.

\section{References}

1. Kassa, E., C. Andersson, and J.C.O. Nielsen, Simulation of dynamic interaction between train and railway turnout. Vehicle System Dynamics, 2006. 44(3): p. 247-258.

2. Cornish, A., R.A. Smith, and J. Dear, Monitoring of strain of in-service railway switch rails through field experimentation. Proceedings of the Institution of Mechanical Engineers, Part F: Journal of Rail and Rapid Transit, 2016. 230(5): p. 1429-1439.

3. $\quad$ CAPACITY4RAIL, Deliverable D1.3: Operational failure modes of S\&Cs. 2014.

4. Hassankiadeh, S.J., Failure Analysis of Railway Switches and Crossings for the purpose of Preventive Maintenance, in Department of Transport Science. 2011, Royal Institute of Technology (KTH): Stockholm.

5. Cornish, A., Life-time monitoring of in service switches and crossings through field experimentation, in Department of Mechanical Engineering. 2014, Imperial College: London.

6. $\quad$ European Commission, In2Rail D2.1: Development of novel S\&C locking mechanisms. Design concept report. 2014.

7. Taylor, J.A., et al., Near-miss narratives from the fire service: a Bayesian analysis. Accident Analysis \& Prevention, 2014. 62: p. 119-129.

8. Ringsberg, J.W., Life prediction of rolling contact fatigue crack initiation. International Journal of fatigue, 2001. 23(7): p. 575-586.

9. Xin, L., V. Markine, and I. Shevtsov, Numerical procedure for fatigue life prediction for railway turnout crossings using explicit finite element approach. Wear, 2016. 366: p. 167-179.

10. Xin, L., V. Markine, and I. Shevtsov, Numerical analysis of the dynamic interaction between wheel set and turnout crossing using the explicit finite element method. Vehicle System Dynamics, 2016. 54(3): p. 301-327.

11. Johansson, A., et al., Simulation of wheel-rail contact and damage in switches \& crossings. Wear, 2011. 271(1-2): p. 472-481.

12. $\mathrm{Xu}, \mathrm{H}$., et al., MedEx: a medication information extraction system for clinical narratives. Journal of the American Medical Informatics Association, 2010. 17(1): p. 19-24.

13. Grimmer, J. and B.M. Stewart, Text as data: The promise and pitfalls of automatic content analysis methods for political texts. Political analysis, 2013. 21(3): p. 267-297.

14. Toyabe, S.-i., Detecting inpatient falls by using natural language processing of electronic medical records. BMC health services research, 2012. 12(1): p. 448.

15. Chase, H.S., et al., Early recognition of multiple sclerosis using natural language processing 
of the electronic health record. BMC medical informatics and decision making, 2017. 17(1): $\mathrm{p}$. 24.

16. Saeeda, L. Iterative Approach for Information Extraction and Ontology Learning from Textual Aviation Safety Reports. in European Semantic Web Conference. 2017. Springer.

17. Mannering, F.L., V. Shankar, and C.R. Bhat, Unobserved heterogeneity and the statistical analysis of highway accident data. Analytic methods in accident research, 2016. 11: p. 1-16.

18. Procter, R., F. Vis, and A. Voss, Reading the riots on Twitter: methodological innovation for the analysis of big data. International journal of social research methodology, 2013. 16(3): p. 197-214.

19. Hughes, P., M. Figueres-Esteban, and C. Van Gulijk. Learning from text-based close call data. in Safety and Reliability. 2016. Taylor \& Francis.

20. Hughes, P., et al., From free-text to structured safety management: Introduction of a semiautomated classification method of railway hazard reports to elements on a bow-tie diagram. Safety Science, 2018.

21. Olofsson, U., et al., Tribology of the wheel/rail contact - aspects of wear, particle emission and adhesion. Vehicle System Dynamics, 2013. 51(7): p. 1091-1120.

22. Tunna, J., J. Sinclair, and J. Perez, A review of wheel wear and rolling contact fatigue. Proceedings of the Institution of Mechanical Engineers, Part F: Journal of Rail and Rapid Transit, 2007. 221: p. 271-290.

23. Office of Rail Regulation, Train derailment at Hatfield: A final report. 2006.

24. Williams, J.A., I.N. Dyson, and A. Kapoor, Repeated loading, residual stresses, shakedown, and tribology. Journal of Materials Research, 1999. 14(4): p. 1548-1559.

25. Network Rail, NR/L2/TRK/001/mod10 Rail profile management. 2012: London.

26. Zerbst, U., et al., Introduction to the damage tolerance behaviour of railway rails - a review. Engineering Fracture Mechanics, 2009. 76: p. 2563-2601.

27. Hughes, P., et al., A computer learning approach to obtain safety information from multilingual accident reports, in Safety and Reliability - Safe Societies in a Changing World: Proceedings of ESREL 2018. 2018, CRC Press / Balkema: Trondheim, Norway. p. 3107-3114.

28. Network Rail, NR/L2/TRK/0053: Inspection and repair to reduce the risk of derailment at switches. 2005: London.

29. WRIST, Deliverable D1.1: Selection of rail section and grade (Confidential). 2015.

30. European Committee For Standardization, EN 14587-1 Railway applications - Infrastructure Flash butt welding of rails - Part 1: New R220, R260, R260Mn, R320Cr, R350HT, R370LHT and R400HT grade rails in a fixed plant. 2016: Brussels.

31. European Committee For Standardization, EN 14730-2 Railway applications - Track Aluminothermic welding of rails - Part 2: Qualification of aluminothermic welders, approval of contractors and acceptance of weld. 2006: Brussels.

32. Network Rail, NR/L1/TRK/002: Categorisation of track. 2011: London.

33. In2Track, Deliverable D2.1: Identifying and understanding the core $S \& C$ issues. 2018.

34. In2Rail, Deliverable D2.5 Radical S\&C concept: Design concept evaluation study report. 2017.

35. Ossberger, H., Modern turnout technology for high speed, in TER Workshop. 2016: Vienna.

36. Nicklisch, D., et al., Geometry and stiffness optimization for switches and crossings, and simulation of material degradation. Proceedings of the Institution of Mechanical Engineers, Part F: Journal of Rail and Rapid Transit, 2010. 224: p. 279-292. 
37. Pålsson, B.A. and J.C.O. Nielsen, Track gauge optimisation of railway switches using a genetic algorithm. Vehicle System Dynamics, 2012. 50(sup1): p. 365-387.

38. Pålsson, B.A., Design optimisation of switch rails in railway turnouts. Vehicle System Dynamics, 2013. 51(10): p. 1619-1639.

39. Bemment, S.D., et al., Rethinking rail track switches for fault tolerance and enhanced performance. Proceedings of the Institution of Mechanical Engineers, Part F: Journal of Rail and Rapid Transit, 2017. 231(9): p. 1048-1065.

40. Foan, A., Methods of operating switches - A comparative study, in RAILWAYS 2018 - Fourth International Conference on Railway Technology: Research, Development and Maintenance, J. Pombo, Editor. 2018: Sitges, Spain.

41. Bezin, Y., et al., Design evaluation of flange back steering for railway switches, in RAILWAYS 2018 - Fourth International Conference on Railway Technology: Research, Development and Maintenance, J. Pombo, Editor. 2018: Sitges, Spain.

42. Grossoni, I., Y. Bezin, and S. Neves, Optimisation of support stiffness at railway crossings. Vehicle System Dynamics, 2018. 56(7): p. 1072-1096.

43. Wan, C., V. Markine, and I. Shevtsov, Optimisation of the elastic track properties of turnout crossings. Proceedings of the Institution of Mechanical Engineers, Part F: Journal of Rail and Rapid Transit, 2016. 230(2): p. 360-373.

44. Pålsson, B.A., Optimisation of railway crossing geometry considering a representative set of wheel profiles. Vehicle System Dynamics, 2015. 53(2): p. 274-301.

45. Pålsson, B.A. and J.C.O. Nielsen, Dynamic vehicle-track interaction in switches and crossings and the influence of rail pad stiffness-field measurements and validation of a simulation model. Vehicle System Dynamics, 2015. 53(6): p. 734-755.

\section{Appendix A}

\begin{tabular}{|c|c|c|c|c|}
\hline Top-level term & Terms & & & \\
\hline \multirow[t]{25}{*}{ defect } & batter & deformation & hole & star crack \\
\hline & battered & deformations & holes & star cracks \\
\hline & battereds & deformed & 1.o.r.b. & star-crack \\
\hline & battering & deteriation & 1.o.r.b.s & star-cracks \\
\hline & batterings & distortion & lipped & starcrack \\
\hline & batters & distortions & lippeds & starcracks \\
\hline & break & distroted & lipping & tache ovale \\
\hline & breaking & fail & lippings & tache ovale defect \\
\hline & breakings & failed & lorb & transverse crack \\
\hline & breaks & fails & lorbs & transverse cracks \\
\hline & broken & failure & porosity & transverse defect \\
\hline & chipped & failures & profile variation & transverse defects \\
\hline & chipping & fault & $\operatorname{rcf}$ & void \\
\hline & chips & faults & scar & voiding \\
\hline & crack & faulty & scarring & wear \\
\hline & cracked & flaked & scars & wear/damage \\
\hline & cracking & flaking & shelling & wheel burn \\
\hline & cracks & flange damage & sidewear & wheel burns \\
\hline & crushed & fsh & sideworn & wheel-burn \\
\hline & crushing & head checking & sidwear & wheel-burns \\
\hline & damage & head checkings & spalled & wheelburn \\
\hline & damages & hogged & spalling & wheelburns \\
\hline & defect & hoggeds & spalls & worn \\
\hline & defective & hogging & squat & \\
\hline & defects & hoggings & squats & \\
\hline \multirow[t]{3}{*}{ operation } & facing move & facing moves & operation & reverse running \\
\hline & facing movement & normal running & operations & trailing moves \\
\hline & facing movements & normal runnings & reverse moves & \\
\hline \multirow[t]{3}{*}{ rail infrastructure } & base plate & crossing noses & mono blocs & stock rails \\
\hline & base plates & crossings & mono-bloc & stockrail \\
\hline & base-plate & diamond & mono-blocs & stockrails \\
\hline
\end{tabular}




\begin{tabular}{|c|c|c|c|c|}
\hline & $\begin{array}{l}\text { base-plates } \\
\text { baseplate } \\
\text { baseplates } \\
\text { bearer } \\
\text { bearers } \\
\text { belly rail } \\
\text { belly rails } \\
\text { blade } \\
\text { blades } \\
\text { cast crossing } \\
\text { cast crossings } \\
\text { casting } \\
\text { castings } \\
\text { chair } \\
\text { chairs } \\
\text { check } \\
\text { check rail } \\
\text { check rails } \\
\text { check-rail } \\
\text { check-rails } \\
\text { checkrail } \\
\text { checks } \\
\text { clamp } \\
\text { clamped } \\
\text { clamping } \\
\text { clampings } \\
\text { clamps } \\
\text { closure } \\
\text { closures } \\
\text { common crossing } \\
\text { common crossings } \\
\text { conductor rail } \\
\text { conductor rails } \\
\text { contact angle } \\
\text { contact angles } \\
\text { contact area } \\
\text { contact surface } \\
\text { contact surfaces } \\
\text { corner } \\
\text { corners } \\
\text { crossing } \\
\text { crossing nose }\end{array}$ & $\begin{array}{l}\text { diamonds } \\
\text { dip angle } \\
\text { dip angles } \\
\text { edge } \\
\text { edges } \\
\text { electrical supply } \\
\text { face } \\
\text { faces } \\
\text { fastener } \\
\text { fasteners } \\
\text { fastenerss } \\
\text { fastening } \\
\text { fastenings } \\
\text { feet } \\
\text { fish plate } \\
\text { fish-plate } \\
\text { fishplate } \\
\text { flange way } \\
\text { flange ways } \\
\text { flange-way } \\
\text { flange-ways } \\
\text { flangeway } \\
\text { flangeways } \\
\text { foot } \\
\text { gauge } \\
\text { gauge corner } \\
\text { gauge face } \\
\text { gauge faces } \\
\text { gauges } \\
\text { grade } \\
\text { grades } \\
\text { head } \\
\text { heads } \\
\text { joint } \\
\text { joints } \\
\text { knuckle } \\
\text { knuckles } \\
\text { leg end } \\
\text { leg ends } \\
\text { midrail } \\
\text { midrails } \\
\text { mono bloc } \\
\text { mand }\end{array}$ & $\begin{array}{l}\text { monobloc } \\
\text { monoblocs } \\
\text { normal position } \\
\text { normal positions } \\
\text { nose } \\
\text { nose topping } \\
\text { nose toppings } \\
\text { noses } \\
\text { obtuse crossing } \\
\text { obtuse crossings } \\
\text { plate } \\
\text { plates } \\
\text { point } \\
\text { point rails } \\
\text { points } \\
\text { profile } \\
\text { profiles } \\
\text { rail } \\
\text { rail bottom } \\
\text { rail bottoms } \\
\text { rail head } \\
\text { rail heads } \\
\text { rail infrastructure } \\
\text { reverse position } \\
\text { rh stock } \\
\text { running edge } \\
\text { running face } \\
\text { running rail } \\
\text { running surface } \\
\text { running table } \\
\text { side wall } \\
\text { sides } \\
\text { sidewall } \\
\text { slide chair } \\
\text { slide chairs } \\
\text { slidechair } \\
\text { slidechairs } \\
\text { splice rail } \\
\text { splice rails } \\
\text { splice-rail } \\
\text { splice-rails } \\
\text { stock rail }\end{array}$ & $\begin{array}{l}\text { stretcher } \\
\text { stretcher bar } \\
\text { surface } \\
\text { surfaces } \\
\text { switch } \\
\text { switch blade } \\
\text { switch panel } \\
\text { switch rail } \\
\text { switch rails } \\
\text { switch toe } \\
\text { switch toes } \\
\text { switch-blade } \\
\text { switchblade } \\
\text { switchblades } \\
\text { switches } \\
\text { toe } \\
\text { toes } \\
\text { topping } \\
\text { transfer area } \\
\text { transfer areas } \\
\text { under side } \\
\text { under-side } \\
\text { underside } \\
\text { untestable rail } \\
\text { vee } \\
\text { vee section } \\
\text { wall } \\
\text { wing } \\
\text { wing rail } \\
\text { wing-rail } \\
\text { wing-rails } \\
\text { wingrail } \\
\text { wingrails } \\
\text { wings } \\
\text { xing } \\
\text { xing nose }\end{array}$ \\
\hline repair & $\begin{array}{l}\text { arc weld } \\
\text { arc welding } \\
\text { arc weldings } \\
\text { arc welds } \\
\text { grind } \\
\text { grinding } \\
\text { grinds } \\
\text { maintenance } \\
\text { metal weld } \\
\text { metal welds } \\
\text { mma }\end{array}$ & $\begin{array}{l}\text { mma repair } \\
\text { mma repairs } \\
\text { mmas } \\
\text { planed } \\
\text { planing } \\
\text { planings } \\
\text { re-profile } \\
\text { re-profiles } \\
\text { repair } \\
\text { reprofile } \\
\text { reprofiles }\end{array}$ & $\begin{array}{l}\text { skv } \\
\text { skv weld } \\
\text { steel insert } \\
\text { steel inserts } \\
\text { t/m/weld } \\
\text { thermic weld } \\
\text { thermit weld } \\
\text { thermite weld } \\
\text { tmz } \\
\text { tri metal } \\
\text { tri metal weld }\end{array}$ & $\begin{array}{l}\text { tri metal welds } \\
\text { tri metalic zone } \\
\text { tri-metal } \\
\text { tri-metallic } \\
\text { trimetal weld } \\
\text { trimetal welds } \\
\text { weld } \\
\text { weld repair } \\
\text { welded } \\
\text { welding } \\
\text { welds }\end{array}$ \\
\hline train & $\begin{array}{l}\text { p } 8 \\
\text { p } 8 \text { s } \\
\text { p. } 8\end{array}$ & $\begin{array}{l}\text { p. } 8 \mathrm{~s} \\
\text { p. } 8 \\
\text { p. } 8 \mathrm{~s}\end{array}$ & $\begin{array}{l}\mathrm{p} 8 \\
\mathrm{p} 8 \mathrm{~s} \\
\text { train }\end{array}$ & wheel \\
\hline
\end{tabular}

